\title{
Interactions between central monoaminergic systems: dopamine-serotonin
}

\author{
G I U S E P E R O C C A T A G L I T A, C L A U D I O ALBANO, \\ LEONARDO COCITO, AND MAURA MAFFINI \\ From the Clinica Neurologica dell'Università di Genova, Genova, Italy
}

S UMMARY Concentration of dopamine and serotonin metabolites (HVA and 5-HIAA) in the CSF was evaluated before and after pharmacological treatment in 19 patients with different neuropsychiatric diseases. In every case a reciprocal modification of the two metabolites occurred after treatment. The result supports the hypothesis of a functional balance between the monoaminergic systems in the central nervous system.

Interactions between systems involving different neurotransmitters in the CNS have been indicated by pharmacoclinical, histochemical, and neurophysiological techniques (Garattini et al., 1978 for review).

A close relationship has been established, for example, between the dopaminergic and the cholinergic system, and their reciprocal connections, both anatomical and functional, explain how an impairment of ore system can enhance the activity of the other (Landinsky et al., 1978). This phenomenon has a relevant clinical application in the treatment of extrapyramidal disorders. Both dopaminergic stimulants and anticholinergic drugs are widely used in Parkinson's disease, whereas in Huntington's chorea, which is commonly regarded as the biochemical counterpart of Parkinsonism, dopamine blocking agents are often successfully employed as well as acetylcholinesterase inhibitors (Barbeau, 1973).

On the other hand, evidence for interaction between the dopaminergic and the serotoninergic systems is unsatisfactory. The two systems display a functional antagonism on common effectors (Hornykiewicz, 1976; Martin et al., 1977), and some neuropharmacological treatments can affect both systems (Pradhan and Bose, 1978). However, the available evidence only suggests that the functional activity of each system may somehow be modified by the other (Green et al., 1976; Heal et al., 1976; Erickson, 1978; Pradhan and Bose, 1978).

Address for reprint requests: Professor G. Roccatagliata, Clinica Neurologica, Via A. de Toni 5, I-16132 Genova, Italy.

Accepted 16 May 1979
Our aim in this study was to investigate the interaction between the dopaminergic and the serotoninergic system, by evaluating the CSF concentration of the main monoamine metabolites before and after a pharmacological treatment.

\section{Patients and methods}

The study was performed on 19 patients (11 men and eight women), aged between 18 and 65 years, with a mean age of 42.7 years. In each case the diagnosis was based on the patient's family and personal history, as well as on neurological examination and psychiatric interview. According to the classification of mental disorders suggested by the American Psychiatric Association (Stengel, 1960), the patients were affected by the following diseases: Huntington's chorea (APA item 19.1), nine cases; manic-depressive reaction, depressed type (item 21.1), eight cases (hereafter referred to as endogenous depression); acute schizophrenic reaction, undifferentiated type (item 22.4), one case; (mild) chronic schizophrenic reaction, paranoid type (item 22.3) associated with tardive dyskinesia, one case (Table 1). All reported cases were inpatients at the Neurological Clinic of the University of Genoa, and gave their informed consent to the procedures.

On admission any pharmacological treatment was discontinued (patients were given only $30 \mathrm{mg}$ flurazepam and $2.5 \mathrm{mg}$ lorazepam as evening medication) and at least 15 days "wash-out" period was observed in every case, until clinical conditions became stable. The first CSF sample (before treatment) was drawn at the end of the 
wash-out period, by lumbar puncture performed at the L2-L3 intervertebral space, with the patient lying on his right side, after he had been resting in bed for at least 10 hours and had not been given any drugs for 12 hours. The puncture was performed at about 9 am. A pharmacological treatment was then started and the drugs and doses for every patient are given in detail in Table 1. As soon as some improvement from the baseline condition was noted a second CSF sample (after treatment) was drawn using the same procedures as before.

Concentrations of HVA and 5-HIAA were evaluated in the first $4 \mathrm{ml}$ of each sample, according to the technique of Korf et al. (1971a, b).

\section{Results}

Levels of HVA and 5-HIAA in the CSF before and after treatment are shown in detail in Table 1. The results obtained from 17 of the 19 patients (those with Huntington's chorea and depression, since cases 2 and 3 were excluded from the computations, being single cases) were evaluated by unweighted means analysis of variance with nested factors (treatment-diagnosis) and repeated measures. A summary of the statistical analysis is given in Table 2. The general impression, that the changes of each metabolite show no unequivocal behaviour in the whole group of patients, was confirmed. However, there was a significant interaction between different treatments (nested within diagnoses) and changes of either metabolite (HVA: $\mathrm{F}(\mathrm{df} 2,13)=19.59, \mathrm{P}<0.001 ; 5$-HIAA: $\mathrm{F}(\mathrm{df} 2,13)$
$=12.06, \mathrm{P}<0.005)$. Such an outcome allows indi- $\mathrm{Z}$ vidual comparisons between "before" and "after" concentrations within single treatment-diagnosis combinations (Table 2).

The most remarkable result, however, was a 0 tendency to reciprocal modifications of HVA and 5-HIAA - that is, a rise of HVA corresponded to a drop of 5-HIAA and vice versa. This is confirmed by the significance of the correlation coefficient between the changes in concentration of $\overrightarrow{\vec{s}}$ the two monoamine metabolites $(r=-0.67 ;$ $\mathrm{P}<0.005$ ).

\section{Discussion}

The determination of the CSF concentration of a single monoamine metabolite can provide only $\overrightarrow{0}$ indirect and unreliable information on the func- $\overrightarrow{\vec{\omega}}$ tional state of the system under investigation $\vec{\sigma}$ (Gessa and Gessa, 1975). It is conceivable, however, that a rise in HVA indicates an increase of dopamine turnover, probably deriving from a higher discharge rate of dopamine producing $\stackrel{\sim}{\mathrm{N}}$ neurones, and that a decrease of dopamine turn- $\vec{N}$ over may be revealed by a drop of HVA in the $\overrightarrow{\vec{F}}$ CSF (Gessa and Gessa, 1975). Similar argumenof can reasonably fit the behaviour of 5-HIAA as index of serotonin metabolism.

A reason for the different behaviour associate with single treatments may be sought in the probable mechanism of action of each drug. Chlorini pramine blocks the re-uptake of serotonin, wher $\overline{\mathbb{Q}}$ as it displays no direct influence on the dop minergic system. A remarkable serotoninergic $\frac{\theta}{6}$

Table 1 Summary of results

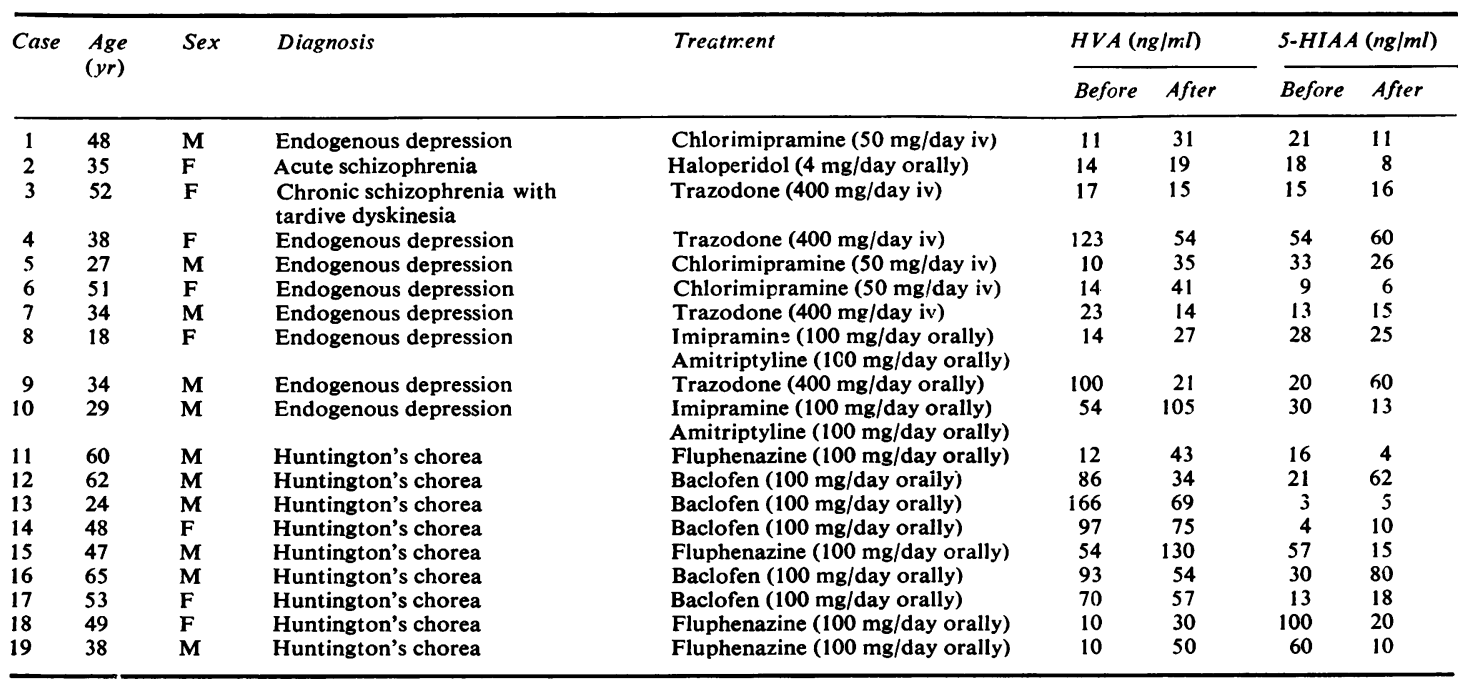


Table 2 Analysis of variance of monoamine metabolite CSF concentrations before and after pharmacological treatment

\begin{tabular}{|c|c|c|c|c|c|}
\hline \multirow[t]{2}{*}{ Source of variation } & \multirow[t]{2}{*}{$d f$} & \multicolumn{2}{|l|}{$H V A$} & \multicolumn{2}{|l|}{$5-H I A A$} \\
\hline & & $S S$ & $F$ & 55 & $F$ \\
\hline $\begin{array}{l}\text { Between subjects } \\
\text { Diagnosis (A) } \\
\text { Treatment (B) under (A) } \\
\text { Error between }\end{array}$ & $\begin{array}{r}16 \\
1 \\
2 \\
13\end{array}$ & $\begin{array}{r}38219.64 \\
2140.38 \\
7693.22 \\
28386.04\end{array}$ & $\begin{array}{l}0.98 \\
1.76\end{array}$ & $\begin{array}{r}9445.16 \\
14.28 \\
1609.47 \\
7821.41\end{array}$ & $\begin{array}{l}0.02 \\
1.34\end{array}$ \\
\hline $\begin{array}{l}\text { Within subjects } \\
\text { Change before-after }(\mathrm{C}) \\
\text { Interaction } \mathrm{A} \times \mathrm{C} \\
\text { Interaction } \mathrm{B}(\mathrm{A}) \times \mathrm{C} \\
\text { Error withi. }\end{array}$ & $\begin{array}{r}17 \\
1 \\
1 \\
2 \\
13\end{array}$ & $\begin{array}{r}19315.50 \\
398.07 \\
252.41 \\
14014.93 \\
4650.09\end{array}$ & $\begin{array}{c}1.11 \\
0.71 \\
19.59 \ddagger\end{array}$ & $\begin{array}{r}8595.00 \\
150.42 \\
560.46 \\
5123.63 \\
2760.48\end{array}$ & $\begin{array}{c}0.71 \\
2.64 \\
12.06 \dagger\end{array}$ \\
\hline Total & 33 & 57535.14 & & 18040.16 & \\
\hline
\end{tabular}

A=diagnosis (A1: Huntington's chorea; A2: Endogenous depression)

B =treatment (B1: Phenothiazines; B2: Baclofen; B3: Tricyclic antidepressants; B 4: Trazodone)

$\mathrm{C}=$ change before-after (C1: Before treatment: $\mathrm{C} 2$ : after treatment)

Individual comparisons (change before-after under single treatment-diagnosis combinations)

\begin{tabular}{|c|c|c|c|c|}
\hline & \multicolumn{2}{|l|}{$H V A$} & \multicolumn{2}{|l|}{$5-H I A A$} \\
\hline & Change & $F$ & Change & $F$ \\
\hline $\begin{array}{l}\text { Phenothiazines (Huntington's chorea) } \\
\text { Baclofen (Huntington's chorea) } \\
\text { Tricyclic antidepressants (Endogerous depression) } \\
\text { Trazodone (Endogenous depression) }\end{array}$ & $\begin{array}{l}+41.75 \\
-44.6 \\
+27.2 \\
-52.33\end{array}$ & $\begin{array}{c}9.91^{*} \\
11.31^{*} \\
4.21 \\
15.57 \dagger\end{array}$ & $\begin{array}{r}-46.0 \\
+20.8 \\
-8.0 \\
+16.0\end{array}$ & $\begin{array}{c}20.27 \ddagger \\
4.14 \\
0.61 \\
2.45\end{array}$ \\
\hline
\end{tabular}

$* \mathbf{P}<0.01$
$0 P$

$\dagger=\mathrm{P}<0.005$

$\ddagger=P<0.001$

action is shared also by amitriptyline and imipramine, which probably have no effect at all on the dopaminergic system (Goodwin et al., 1978). The drop of CSF 5-HIAA after treatment with tricyclic antidepressants substantiates the hypothesis of their serotoninergic action (Goodwin and Post, 1975).

The effect of trazodone on the central monoaminergic systems is at present rather uncertain. Dopamine stimulating properties were previously demonstrated by Garattini (1974) and Hontela and Nair (1975), but at very high doses the drug has been reported to have a blocking action on serotonin re-uptake quite similar to that of chlorimipramine (for reference see Silvestrini, 1978). The drop of HVA in our cases is consistent with the dopamine stimulating properties (Roos, 1969; Corrodi et al., 1972; Garattini et al., 1972), and we were not able to confirm the serotonin reuptake blocking properties since a rise in 5-HIAA occurred.

Fluphenazine, like other phenothiazines, reveals its effect of blocking dopaminergic receptors by increasing CSF HVA concentration (Goodwin and Post, 1975).

Baclofen, which is reported to decrease the rate of discharge of dopamine producing neurones
(Carlsson et al., 1977), actually causes a drop in HVA, as described in a previous report (Roccatagliata et al., 1978).

In every patient in this study, reciprocal changes of HVA and 5-HIAA occurred after pharmacological treatment, indicating that an increase of dopamine turnover is associated with a decrease of serotonin turnover and vice versa.

In view of these data, the observation that response to treatment was never limited to a single monoaminergic system but always involved both, makes it conceivable that a drug-induced "primary" change in either system causes a new functional adjustment of the other, as a result of a real interaction.

These data are consistent with some previous reports (Erickson, 1978; Pradhan and Bose, 1978). Although they need further confirmation (since, for instance, we did not use the probenecid technique), they disclose new prospects for study. Some current opinions on the pathogenesis of extrapyramidal disorders and psychoses, inferred mainly from the response to different drugs, ascribe these diseases to the impairment of a single monoaminergic system. They should be revised after consideration of the kind of balance shown by our studies. 


\section{References}

Barbeau, A. (1973). Biochemistry of Huntington's chorea. In Advances in Neurology, vol. 1, pp. 473516. Edited by A. Barbeau, T. N. Chase, and G. W. Paulson. Raven Press: New York.

Carlsson, A., Biswas, B., and Linquist, H. (1977). Influence of Gaba and Gaba-like drugs on monoaminergic mechanisms. In Advances in Biochemical Psychopharmacology, vol. 16, pp. 471-475. Edited by E. Costa and G. L. Gessa. Raven Press: New York.

Corrodi, H., Farnebo, L. C., Fuxe, K., Hamburger, B., and Ungerstedt, U. (1972). ET 495 and brain catecholamine mechanisms: evidence for stimulation of dopamine receptors. European Journal of Pharmacology, 20, 195-207.

Erickson, C. K. (1978). Functional relationships among central neurotransmitters. In Reviews of Neuroscience, vol. 3, pp. 1-34. Edited by J. Ehrenpreis and J. Kopin. Raven Press: New York.

Garattini, S. (1974). Biochemical studies with trazodone. In Modern Problems of Pharmacopsychiatry. Trazodone, pp. 29-46. Edited by T. A. Ban and B. Silvestrini. Karger: Basel.

Garattini, S., Fanelli, R., Iori, A., Consolo, S., Landinsky, H., and Samanin, R. (1972). Pharmacological and biochemical studies on Piribedil. Proceedings of the International Symposium on Trivastal, Monastir.

Garattini, S., Pujol, J. F., and Samanin, R. (1978). Interactions between Putative Neurotransmitters in the Brain. Raven Press: New York.

Gessa, G., and Gessa, R. (1975). Significato dei metaboliti delle monoamine cerebrali in rapporto alla funzione neuronale. Communication to the 19th Congresso Nazionale della Società Italiana di Neurologia, Genova, December 3-6.

Goodwin, F. K., Cowdry, R. W., and Webster, M. H. (1978). Predictors of drug response in the affective disorders: toward an integrated approach. In Psychopharmacology: A Generation of Progress, pp. 1277-1288. Edited by M. A. Lipton, A. Di Mascio, and K. F. Killam. Raven Press: New York.

Goodwin, F. K., and Post, R. M. (1975). Studies of amine metabolites in affective illness and in schizophrenia: a comparative analysis. In Biology of the Major Psychoses, pp. 299-332. Edited by D. X. Freedman. Raven Press: New York.

Green, A. R., Youdin, M. B. H., and GrahameSmith, D. G. (1976). Quipazine: its effects on rat brain 5-HT metabolism, monoaminoxidase activity and behavior. Neuropharmacology, 15, 173-179.

Heal, D. J., Green, A. R., Boullin, D. J., and Grahame-Smith, D. G. (1976). Single and repeated administration of neuroleptic drugs to rats: effects on striatal dopamine sensitive adenylate cyclase and $\stackrel{\mathcal{D}}{\mathcal{C}}$ locomotor activity produced by tranylcypromine and L-tryptophan and L-dopa. Psychopharmacology, 49, 287-300.

Hontela, S., and Nair, N. P. V. (1975). Trazodone in 0 geriatric patients with organic brain syndrome. Pro ceedings of the 3rd World Congress of ICPM, pp. $\frac{\bigcirc}{\supset}$ 119-124. Rome, September 16-20.

Hornykiewicz, O. (1976). Neurohumoral interactions and basal ganglia. Function and dysfunction. In The Basal Ganglia, pp. 269-280. Edited by M. D. Yahr. Raven Press: New York.

Korf, J., Ottema, S., and Van der Veen, I. (1971a). $\frac{\mathrm{C}}{\sigma}$ Fluorometric determination of homovanillic acid in $\overline{\bar{\omega}}$ biological material after isolation on sephadex G-10. $\stackrel{\overparen{D}}{\mathrm{Q}}$ Analytical Biochemistry, 40, 187-191.

Korf, J., Van Praag, H. M., and Sebens, J. B. (1971b). ొొ Effect of intravenously administered probenecid in humans on the levels of 5-hydroxyindoleacetic acid, homovanillic acid and 3-methoxy-4-hydroxy-phenyl- $\overrightarrow{\vec{\omega}}$ glycol in cerebrospinal fluid. Biochemical Pharmacology, 20, 659-668.

Landinsky, H., Consolo, S., Bianchi, S., Ghezzi, D., and Samanin, R. (1978). Link between dopaminergic and cholinergic neurons in the striatum as evi-? denced by pharmacological, biochemical and lesion $\vec{N}$ studies. In Interactions between Putative Neurw $\rightarrow$ transmitters in the Brain, pp. 3-21. Edited by $\vec{S} \cdot \vec{G}$ Garattini, J. F. Pujol, and R. Samanin. Rave्d Press: New York.

Martin, J. B., Reichlin, S., and Brown, G. M. (197 Hypothalamic control. In Clinical Endocrinolog pp. 45-59. Edited by J. B. Martin, S. Reichlin, argd G. M. Brown. F. A. Davis Company: Philadelphia. $\frac{\mathbb{Q}}{3}$

Pradhan, S. N., and Bose, S. (1978). Interactioms among central neurotransmitters. In Psychopharm cology: A Generation of Progress, pp. 271-281. $\overrightarrow{0}$ Edited by M. A. Lipton, A. Di Mascio, and K. F. Vै Killam. Raven Press: New York.

Roccatagliata, G., Albano, C., Besio, G., and Ivaldi, M. (1978). Discinesie coreiche e Gaba. Approccio farmaco-clinico. Archivio Svizzero di Neurologia, $\overline{0}$ Neurochirurgia e Psichiatria, 123, 63-68.

Roos, B. E. (1969). Decrease of HVA as evidence for $\stackrel{\square}{\perp}$ dopamine receptor stimulation by apomorphine in the neostriatum of the rat. Journal of Pharmacy and Pharmacology, 21, 263-264.

Silvestrini, B. (1978). Trazodone: a new approach to the therapy of depression. In Depression and the Role of Trazodone in Antidepressant Therapy, pp. 1-10. Edited by G. Morozov, B. Saarma, and B. Silvestrini. Edizioni Luigi Pozzi: Rome.

Stengel, E. (1960). Classification of mental disorders. $\frac{0}{3}$ Bulletin of the World Health Organisation, 21, 601-663. 